medRxiv preprint doi: https://doi.org/10.1101/2021.08.12.21261493; this version posted September 21 , 2021. The copyright holder for this preprint (which was not certified by peer review) is the author/funder, who has granted medRxiv a license to display the preprint in

All rights reserved. No reuse allowed without permission.

\title{
A causal association between schizophrenia and bipolar disorder on rheumatoid arthritis: A two-sample Mendelian randomization study
}

Gonul Hazal Koc ${ }^{1}$, Fatih Ozel ${ }^{2}$, Kaan Okay ${ }^{3,4}$, Dogukan Koc ${ }^{5,6^{*}}$, Pascal H.P. de Jong ${ }^{7}$

${ }^{1}$ Department of Internal Medicine, Izmir Katip Celebi University Faculty of Medicine, Izmir, Turkey

${ }^{2}$ Environmental Toxicology, Department of Organismal Biology, Uppsala University, Uppsala, Sweden

${ }^{3}$ Izmir International Biomedicine and Genome Institute, Dokuz Eylul University, Izmir, Turkey

${ }^{4}$ Izmir Biomedicine and Genome Center, Dokuz Eylul University Health Campus, Izmir, Turkey

${ }^{5}$ Department of Child and Adolescent Psychiatry, Dokuz Eylul University, Izmir, Turkey

${ }^{6}$ Department of Child and Adolescent Psychiatry/Psychology, Erasmus MC, University Medical Center Rotterdam, Rotterdam, the Netherlands

${ }^{7}$ Department of Rheumatology, Erasmus MC, Rotterdam, The Netherlands

*Corresponding Author at Department of Child and Adolescent Psychiatry/Psychology, Erasmus MC, University Medical Center Rotterdam, Rotterdam, the Netherlands

E-mail address: d.koc@erasmusmc.nl 
medRxiv preprint doi: https://doi.org/10.1101/2021.08.12.21261493; this version posted September 21 , 2021. The copyright holder for this preprint (which was not certified by peer review) is the author/funder, who has granted medRxiv a license to display the preprint in

All rights reserved. No reuse allowed without permission.

\begin{abstract}
Background: Schizophrenia (SCZ) and bipolar disorder (BD) are both associated with several autoimmune disorders including rheumatoid arthritis(RA). However, a causal association of SCZ and BD on RA is controversial and elusive. In the present study, we aimed to investigate the causal association of SCZ and BD with RA by using the Mendelian randomization (MR) approach.
\end{abstract}

Methods: A two-sample MR (2SMR) study including the inverse-variance weighted(IVW), weighted median, simple mode, weighted mode and MR-Egger methods were performed. We used summary-level genome-wide association study(GWAS) data in which BD and SCZ are the exposure and RA the outcome. We used data from the Psychiatric Genomics Consortium(PGC) for $\mathrm{BD}(\mathrm{n}=41,917)$ and $\mathrm{SCZ}(\mathrm{n}=33,426)$ and RA GWAS dataset $(\mathrm{n}=2,843)$ from the European ancestry for RA.

Results: We found 48 and 52 independent single nucleotide polymorphisms (SNPs, r2 $<0.001)$ ) that were significant for respectively BD and SCZ ( $<5 \times 10-8)$. Subsequently, these SNPs were utilized as instrumental variables(IVs) in 2SMR analysis to explore the causality of $\mathrm{BD}$ and SCZ on RA. The two out of five MR methods showed a statistically significant inverse causal association between BD and RA: weighted median method(odds ratio (OR), 0.869, [95\% CI, 0.764-0.989]; $P=0.034)$ and inverse-variance weighted(IVW) method (OR, 0.810, [95\% CI, 0.689-0.953]; $P=0.011)$. However, we did not find any significant association of SCZ with RA (OR, 1.008, [95\% CI, 0.931-1.092]; $P=0.829$, using the IVW method).

Conclusions: These results provide support for an inverse causal association between BD and RA. Further investigation is needed to explain the underlying protective mechanisms in the development of RA.

Key words: Bipolar disorder; Schizophrenia; Rheumatoid arthritis; Genome-wide association study, Mendelian randomization; Single nucleotide polymorphism 
medRxiv preprint doi: https://doi.org/10.1101/2021.08.12.21261493; this version posted September 21 , 2021. The copyright holder for this preprint (which was not certified by peer review) is the author/funder, who has granted medRxiv a license to display the preprint in

All rights reserved. No reuse allowed without permission.

\section{Key messages}

- Mendelian randomization can offer strong insight into the cause-effect relationships in rheumatology.

- Bipolar disorder had a protective effect on rheumatoid arthritis.

- There is no inverse causal association between schizophrenia and rheumatoid arthritis contrary to the findings from observational studies.

\section{Introduction}

Schizophrenia (SCZ) and bipolar disorder (BD) are severe psychiatric disorders that are characterized by significant emotional, cognitive and behavioral symptoms, and they cause substantial deterioration in functioning $[1,2]$. Both disorders pose an increased risk of morbidity and mortality and are associated with decreased life expectancy [3-5]. Genetic factors have been investigated for SCZ [6] and the interplay between genetic and environment has also been a focus [7,8]. Still, the etiopathogenesis of SCZ seems heterogeneous, and the existing evidence remains inconclusive. Many risk factors have also been identified for BD in a similar manner [9]. However, our understanding of the biological underpinnings is limited. Notwithstanding, disturbances in inflammatory signaling mechanisms seem to play a critical role in the etiopathogenesis of SCZ and BD $[10,11]$. For example, several studies have shown that autoimmune disorders are more prevalent in SCZ and BD compared to the general population, but potential confounders were not always addressed correctly [12, 13].

Rheumatoid arthritis (RA) on the other hand is a common autoimmune disorders that is caused by an dysregulation of the immune system [14]. The disease may cause severe function impairment [15]. RA is also accompanied with several comorbidities, that can have a severe impact on patients' lives. One of these comorbidities might be psychiatric disorders on which we will focus.

Population-based studies mainly demonstrated the lower prevalence of RA in patients with SCZ [16-18]. The possible explanations for the lower prevalence of RA and SCZ have not been examined comprehensively, and the lack of evidence raises the demand for exploring this relationship with various potent methods. On the other hand, the high comorbidity of RA has been speculated for BD in the literature. Two different case-control studies demonstrated a 
medRxiv preprint doi: https://doi.org/10.1101/2021.08.12.21261493; this version posted September 21, 2021. The copyright holder for this preprint (which was not certified by peer review) is the author/funder, who has granted medRxiv a license to display the preprint in

All rights reserved. No reuse allowed without permission.

higher prevalence of RA among patients with BD [19, 20]. The increased risk of developing $\mathrm{BD}$ in persons with RA has also been established in population-based settings [21-23]. Even though, a high prevalence of BD among patients with RA has been shown in another casecontrol study [24], the association between BD and RA was not significant in the multivariate analysis, which posits the importance of potential confounding.

Although aforementioned findings suggest that the prevalence of RA is lower in SCZ and higher in $\mathrm{BD}$, the evidence is still limited and the causal relationships are yet to be established. Nonetheless, inflammatory disturbances seem to be the main reason for the associations between these psychiatric disorders and RA; potential confounders need to be investigated thoroughly, to avoid biased associations. Regrettably, observational studies are limited to capture many confounders, and experimental designs carry other difficulties to conduct to scrutinize the co-existence of RA and SCZ or BD. Mendelian randomization (MR) may be a favorable solution to circumvent these shortcomings and explores the causation of a relationship between exposure and an outcome using genetic variants. MR is a robust epidemiological method that uses the genetic variants related to the exposure of interest to make causal inferences about the non-genetic measures of the outcome [25]. MR exploits single-nucleotide polymorphisms (SNPs) as instrumental variables (IVs) for the exposure [26]; thus, it can evade the issues caused by confounding and provide more accurate causal interpretations. MR can be a cost-effective solution for clinical studies that might otherwise be extremely costly, technically or ethically difficult. To our best knowledge, no MR study has been performed previously to explore the causality between RA and SCZ or BD. Therefore, our aim is to investigate the potential causal relationship between having SCZ or BD and the risk of developing RA.

\section{Materials and methods}

We performed a two-sample mendelian randomization (2SMR) approach to assess causality between BD, SCZ, and RA using publicly available GWAS summary datasets.

\section{Data sources}

We downloaded the latest GWAS summary data with BD I and II, which includes 7,608,183 single nucleotide polymorphisms (SNPs) of 41,917 cases and 371,549 controls [27] 
medRxiv preprint doi: https://doi.org/10.1101/2021.08.12.21261493; this version posted September 21, 2021. The copyright holder for this preprint (which was not certified by peer review) is the author/funder, who has granted medRxiv a license to display the preprint in

All rights reserved. No reuse allowed without permission.

and the SCZ GWAS data including 8,379,106 SNPs of 33,426 cases and 32,541 controls [28] from the Psychiatric Genomics Consortium database (https://www.med.unc.edu/pgc/). The RA GWAS summary data included 8,514,610 SNPs of 2,843 cases and 5,540 controls [29] and was downloaded from the Japanese ENcyclopedia of GEnetic associations by Riken database (http://jenger.riken.jp/en/result). All GWAS summary data are based on European ancestry.

\section{Instrument identification}

We used the R package TwoSampleMR v0.5.6 to harmonize SNP information and conducted a 2SMR analysis between BD, SCZ, and RA [30]. All GWAS data had beta coefficient $(\beta)$, standard error of $\beta$ (SE), major and minor alleles for each SNP together with the allele frequencies, $p$-value for relevant association, and total sample size information. We followed four steps in the analysis: $i)$ genome-wide significant SNPs $\left(p \leq 5 \times 10^{-8}\right)$ related to exposure were selected as (IVs) (IVs); ii) linkage disequilibrium (LD) pruning $\left(\mathrm{r}^{2}<0.001\right)$ was performed to obtain independent SNPs; iii) genome-wide significant and independent SNPs were extracted from outcome GWAS data and those SNPs were utilized in harmonization of exposure and outcome GWAS data to ensure their effect on those data to correspond to the same allele; $i v$ ) harmonized data were used in a 2SMR analysis. Eventually, we identified 48 and 52 independent SNPs at genome-wide significance from respectively BD and SCZ GWAS data. These SNPs were used as IVs for harmonization, MR, heterogeneity, and sensitivity analyses in the R computation environment v4.1.0 (http://www.R-project.org).

\section{Two-sample Mendelian randomization}

The $\beta$ and SE were used in the estimation of the causal relationship. We obtained MR results for the following five methods: Inverse-variance weighted (IVW) [31], MR-Egger [32], weighted median [33], weighted mode and simple mode [34]. Either BD or SCZ were the exposure and RA was for both exposures the outcome. The respectively 48 and 52 independent SNPs were used as IVs in the 2SMR analysis. Subsequently, the aforementioned five MR methods were utilized to generate effect size estimates of these SNPs. 
medRxiv preprint doi: https://doi.org/10.1101/2021.08.12.21261493; this version posted September 21, 2021. The copyright holder for this preprint (which was not certified by peer review) is the author/funder, who has granted medRxiv a license to display the preprint in

All rights reserved. No reuse allowed without permission.

\section{Sensitivity analyses}

Sensitivity analyses were performed to examine the existence of horizontal pleiotropy and heterogeneity. In the case of horizontal pleiotropy, a single locus can affect an outcome through one or more biological pathways independent of that of the assumed exposure. To test the horizontal pleiotropic effect amongst BD, SCZ, and RA, we performed MR-Egger regression analysis. Furthermore, we employed the leave-one-out analysis, where one variant that is strongly associated with exposure and dominates the estimate of the causal effect is removed from the analysis to re-estimate the causal effect.

\section{Results}

After genome-wide significance filtering, LD pruning, and harmonization of potential SNPs, 48 BD and 52 SCZ independent genome-wide significant SNPs were considered as IVs. These IVs were used in a $2 \mathrm{SMR}$ analysis to estimate the causality of BD and SCZ on RA. The detailed information on these IVs can be found in Supplementary Table S1 and S2. The relationship is represented as odds ratios (ORs) with respective p-values in Table 1.

We used five MR methods to estimate the causality of BD and SCZ on RA. We found an inverse causal association between BD and RA. MR methods weighted median $(\mathrm{OR}=0.869$, [95\% CI 0.764-0.989]; $P=0.034)$ and IVW (OR=0.810, [95\% CI 0.689-0.953]; $P=0.011)$ were significant, while the other methods were not (MR Egger $(\mathrm{OR}=0.652$, [95\% CI 0.2961.434]; $P=0.293)$, simple mode $(\mathrm{OR}=0.905$, [95\% CI 0.686-1.195]; $P=0.488)$, and weighted mode $(\mathrm{OR}=0.879$, [95\% CI 0.678-1.139]; $P=0.336$ ). These estimates are available in Figure 1A and Table 1 in detail. We also performed a leave-one-out analysis and did not find a notable effect of any single SNP that could dominate the results (Supplementary Figure S1). The funnel plot did not signify that there were heterozygous SNPs (Figure 1B). We did not find evidence for pleiotropy from the MR-Egger regression (intercept: $0.015, P=0.583$ ). The heterogeneity results can be found in Supplementary Table S3. On the other hand, no statistical significance in the causal relationship between SCZ and RA was found (Table 1). More detailed results of these estimations are presented as respectively scatter and funnel plots in Figure 1C-D. 
medRxiv preprint doi: https://doi.org/10.1101/2021.08.12.21261493; this version posted September 21, 2021. The copyright holder for this preprint (which was not certified by peer review) is the author/funder, who has granted medRxiv a license to display the preprint in

All rights reserved. No reuse allowed without permission.

\section{Discussion}

We performed 2SMR analyses to explore the causality between SCZ, BD and RA based on summary statistics of the largest available GWAS to date. Our analyses suggested that BD had a protective effect on RA, whereas SCZ had no significant effect on RA. Considering the power of the MR approach on the exclusion of confounding factors, the effects of environmental factors can be decreased because genetic variants are assigned randomly at conception, similar to randomization in a clinical trial. From this standpoint, our study can be considered as the first potential evidence for uncovering causal relationships between psychiatric disorders (SCZ, BD) and RA.

A large number of existing studies in the broader literature have shown an inverse association between SCZ and RA [17, 18, 35-38]. It has been hypothesized that SCZ is a protective factor for RA, some focusing on environmental exposures and immunity, others on misclassification biased by underdiagnosis of $\mathrm{RA}$ in patients with $\mathrm{SCZ}[18,39,40]$. A recent population-based case-control study from Sweden demonstrated that patients with SCZ have a decreased risk of developing RA (hazard ratio $[\mathrm{HR}]=0.69,95 \% \mathrm{CI}=0.59-0.80$ ) [18].Similar results were found in the Danish Psychiatric Case Register study involving 20,495 patients with SCZ and 204,912 randomly selected age- and sex-matched controls (HR=0.44, 95\% CI $=0.24-0.81$ ) [17]. Our finding contradict aforementioned studies. A possible explanation might be that causal evidence from observational studies are effected by (un)known confounding factors. For example, the mean age of onset for RA is usually later in life than SCZ and comorbid medical conditions are tend to be underreported in patients with SCZ [18, 19], which might be the case of the found decreased risk in these case-control studies. Therefore, it is important that screening for comorbidities in SCZ patients should be done more thoroughly, which is also supported by our results.

Various clinical studies have been conducted in the past to study the co-occurrence of BD and RA [19, 21, 41]. Nevertheless, the association between BD and RA remained unclear and debatable. For example, a Swedish register study in a sample of 3,798 patients with BD and 6,485 controls showed a greater risk for RA in BD compared to controls [19]. Similar results were found in a Danish and Taiwan registry [21, 41]. On the other hand, a large Swedish Population Registry showed a similar incidence of RA in patients with BD [18]. In this registry 34,744 patients with BD were included, who had a relative risk of developing RA of 1.01 
medRxiv preprint doi: https://doi.org/10.1101/2021.08.12.21261493; this version posted September 21, 2021. The copyright holder for this preprint (which was not certified by peer review) is the author/funder, who has granted medRxiv a license to display the preprint in

All rights reserved. No reuse allowed without permission.

(0.96 - 1.06, 95\% CI). Moreover, a nationally representative longitudinal study from the Netherlands showed that having any mood or any anxiety disorder did not predict new-onset arthritis [42]. However, several inevitable confounding factors in observational studies are not adequately addressed in the literature. In the present study, we aimed to clarify the causal association between BD and RA. Although our analysis showed that patients with BD had a lower chance of developing RA, the reasons behind this protective effect are yet unclear. Fortunately, several studies already investigated the relationship between autoimmune disorders and severe psychiatric conditions, including BD and SCZ [43-46]. Immunity and gene-environment interactions represent a major risk factor for these disorders [47-50]. The studies showed that the major histocompatibility complex (MHC) was one of the best validated genetic susceptibility loci for major psychiatric and autoimmune disorders [44, 51, 52]. A growing body of evidence also suggested that $\mathrm{MHC}$ involvement is more prominent in SCZ compared to $\mathrm{BD}$ [51]. Interestingly, some $\mathrm{MHC}$ loci have been revealed to contribute predisposition to certain autoimmune conditions while others are protective [44]. Therefore, it is important to highlight the fact that the prevalence of comorbid autoimmune conditions in BD and SCZ differ significantly, which is also seen in our results [19].

The present study has several strengths. We used the latest accessible and analyzable BD GWAS data providing confidence in MR assumptions to estimate the causality. All participants in the GWAS data were of European ancestry, which facilitated the elimination of confounding factors stemming from different races. Furthermore, we observed no horizontal pleiotropy, that is, the outcome directly affected by IVs of exposure without confounding. This provides robust causality of BD on RA and eases the interpretation of the genetic basis of the relationship. A potential limitation of our study is that in the direction of BD to RA, effect size estimates had borderline significance, which could be due to relatively limited sample size and/or low causal relationship. Also, we postulated a linear relationship between exposure and outcome, while using summary data that excluded other interactions (e.g., gene-gene and geneenvironment). This might have led to deviations from this linearity. Finally, the clumping algorithm that identified the correlated genetic variants depended solely on European samples, because of the lack of corresponding data from other populations. This makes it hard to generalize the data to other populations (e.g. Asian). 
medRxiv preprint doi: https://doi.org/10.1101/2021.08.12.21261493; this version posted September 21 , 2021. The copyright holder for this preprint (which was not certified by peer review) is the author/funder, who has granted medRxiv a license to display the preprint in All rights reserved. No reuse allowed without permission.

In conclusion, we found no causal association between SCZ and RA, which contradicts current knowledge, and therefore we advise to screen SCZ more thoroughly for joint complaints. On the other hand the risk of RA is reduced in $\mathrm{BD}$, however future studies are necessary to explore the biological mechanisms underlying this genetically predicted relationship.

\section{Ethics approval and consent to participate}

The present study used only publicly available summary-level statistics. No individual-level data was analyzed. Ethical approval is therefore not required.

\section{Data accessibility and code availability}

Only publicly available data were used in this study. Data sources and handling of these data are described in the Materials and methods. The codes can be found in $\mathrm{R}$ package TwoSampleMR.

\section{Competing interests}

The authors declare that they have no conflicts of interest with the contents of this article.

\section{Funding}

Not applicable

\section{Acknowledgements}

The authors thank all individuals who shared GWAS summary statistics. 
medRxiv preprint doi: https://doi.org/10.1101/2021.08.12.21261493; this version posted September 21, 2021. The copyright holder for this preprint (which was not certified by peer review) is the author/funder, who has granted medRxiv a license to display the preprint in perpetuity.

All rights reserved. No reuse allowed without permission.

\section{References}

1 Kahn RS, Sommer IE, Murray RM, et al. Schizophrenia. Nature Reviews Disease Primers 2015;1(1):15067.

2 Vieta E, Berk M, Schulze TG, et al. Bipolar disorders. Nature Reviews Disease Primers 2018;4(1):18008.

$3 \quad$ Kessing LV, Vradi E, Andersen PK. Life expectancy in bipolar disorder. Bipolar Disord 2015;17(5):543-8.

$4 \quad$ Kilbourne AM, Morden NE, Austin K, et al. Excess heart-disease-related mortality in a national study of patients with mental disorders: identifying modifiable risk factors. Gen Hosp Psychiatry 2009;31(6):555-63.

5 Laursen TM. Life expectancy among persons with schizophrenia or bipolar affective disorder. Schizophr Res 2011;131(1-3):101-4.

$6 \quad$ Bulik-Sullivan B, Finucane HK, Anttila V, et al. An atlas of genetic correlations across human diseases and traits. Nat Genet 2015;47(11):1236-41.

7 Trotta A, lyegbe C, Yiend $\mathrm{J}$, et al. Interaction between childhood adversity and functional polymorphisms in the dopamine pathway on first-episode psychosis. Schizophr Res 2019;205:51-7.

8 Vassos E, Kou J, Tosato S, et al. Lack of Support for the Genes by Early Environment Interaction Hypothesis in the Pathogenesis of Schizophrenia. Schizophr Bull 2021.

9 Rowland TA, Marwaha S. Epidemiology and risk factors for bipolar disorder. Ther Adv Psychopharmacol 2018;8(9):251-69.

10 Jones GH, Vecera CM, Pinjari OF, Machado-Vieira R. Inflammatory signaling mechanisms in bipolar disorder. J Biomed Sci 2021;28(1):45.

11 Müller N. Inflammation in Schizophrenia: Pathogenetic Aspects and Therapeutic Considerations. Schizophr Bull 2018;44(5):973-82.

12 Benros ME, Nielsen PR, Nordentoft M, Eaton WW, Dalton SO, Mortensen PB. Autoimmune diseases and severe infections as risk factors for schizophrenia: a 30-year population-based register study. Am J Psychiatry 2011;168(12):1303-10.

13 SayuriYamagata A, Brietzke E, Rosenblat JD, Kakar R, Mclntyre RS. Medical comorbidity in bipolar disorder: The link with metabolic-inflammatory systems. J Affect Disord 2017;211:99-106.

14 Smolen JS, Aletaha D, Mclnnes IB. Rheumatoid arthritis. Lancet 2016;388(10055):2023-38.

15 Cross M, Smith E, Hoy D, et al. The global burden of rheumatoid arthritis: estimates from the global burden of disease 2010 study. Ann Rheum Dis 2014;73(7):1316-22.

16 Chen SF, Wang LY, Chiang JH, Hsu CY, Shen YC. Assessing whether the association between rheumatoid arthritis and schizophrenia is bidirectional: A nationwide populationbased cohort study. Sci Rep 2019;9(1):4493.

17 Mors $\mathrm{O}$, Mortensen $\mathrm{PB}$, Ewald $\mathrm{H}$. A population-based register study of the association between schizophrenia and rheumatoid arthritis. Schizophrenia Research 1999;40(1):67-74.

18 Sellgren C, Frisell T, Lichtenstein P, Landèn M, Askling J. The Association Between Schizophrenia and Rheumatoid Arthritis: A Nationwide Population-Based Swedish Study on Intraindividual and Familial Risks. Schizophrenia Bulletin 2014;40(6):1552-9.

19 Cremaschi L, Kardell M, Johansson V, et al. Prevalences of autoimmune diseases in schizophrenia, bipolar I and II disorder, and controls. Psychiatry Research 2017;258:9-14.

20 Forty L, Ulanova A, Jones L, et al. Comorbid medical illness in bipolar disorder. Br J Psychiatry 2014;205(6):465-72.

21 Hsu C-C, Chen S-C, Liu C-J, et al. Rheumatoid Arthritis and the Risk of Bipolar Disorder: A Nationwide Population-Based Study. PLOS ONE 2014;9(9):e107512.

22 Marrie RA, Hitchon CA, Walld R, et al. Increased Burden of Psychiatric Disorders in Rheumatoid Arthritis. Arthritis Care Res (Hoboken) 2018;70(7):970-8. 
medRxiv preprint doi: https://doi.org/10.1101/2021.08.12.21261493; this version posted September 21, 2021. The copyright holder for this preprint (which was not certified by peer review) is the author/funder, who has granted medRxiv a license to display the preprint in

All rights reserved. No reuse allowed without permission.

23 Wang LY, Chiang JH, Chen SF, Shen YC. Systemic autoimmune diseases are associated with an increased risk of bipolar disorder: A nationwide population-based cohort study. J Affect Disord 2018;227:31-7.

24 Farhi A, Cohen AD, Shovman O, Comaneshter D, Amital H, Amital D. Bipolar disorder associated with rheumatoid arthritis: A case-control study. J Affect Disord 2016;189:287-9.

25 Lawlor DA, Harbord RM, Sterne JA, Timpson N, Davey Smith G. Mendelian randomization: using genes as instruments for making causal inferences in epidemiology. Stat Med 2008;27(8):1133-63.

26 Davies NM, Holmes MV, Davey Smith G. Reading Mendelian randomisation studies: a guide, glossary, and checklist for clinicians. Bmj 2018;362:k601.

27 Mullins N, Forstner AJ, O'Connell KS, et al. Genome-wide association study of more than 40,000 bipolar disorder cases provides new insights into the underlying biology. Nat Genet 2021;53(6):817-29.

28 Ruderfer DM, Ripke S, McQuillin A, et al. Genomic Dissection of Bipolar Disorder and Schizophrenia, Including 28 Subphenotypes. Cell 2018;173(7):1705-15.e16.

29 Okada Y, Wu D, Trynka G, et al. Genetics of rheumatoid arthritis contributes to biology and drug discovery. Nature 2014;506(7488):376-81.

30 Hemani G, Zheng J, Elsworth B, et al. The MR-Base platform supports systematic causal inference across the human phenome. Elife 2018;7.

31 Burgess S, Butterworth A, Thompson SG. Mendelian Randomization Analysis With Multiple Genetic Variants Using Summarized Data. Genetic Epidemiology 2013;37(7):658-65. 32 Bowden J, Davey Smith G, Burgess S. Mendelian randomization with invalid instruments: effect estimation and bias detection through Egger regression. International Journal of Epidemiology 2015;44(2):512-25.

33 Bowden J, Davey Smith G, Haycock PC, Burgess S. Consistent Estimation in Mendelian Randomization with Some Invalid Instruments Using a Weighted Median Estimator. Genetic Epidemiology 2016;40(4):304-14.

34 Hartwig FP, Davey Smith G, Bowden J. Robust inference in summary data Mendelian randomization via the zero modal pleiotropy assumption. International Journal of Epidemiology 2017;46(6):1985-98.

35 Benros ME, Eaton WW, Mortensen PB. The Epidemiologic Evidence Linking Autoimmune Diseases and Psychosis. Biological Psychiatry 2014;75(4):300-6.

36 Malavia TA, Chaparala S, Wood J, et al. Generating testable hypotheses for schizophrenia and rheumatoid arthritis pathogenesis by integrating epidemiological, genomic, and protein interaction data. npj Schizophrenia 2017;3(1):11.

37 Chen S-J, Chao Y-L, Chen C-Y, et al. Prevalence of autoimmune diseases in inpatients with schizophrenia: nationwide population-based study. The British Journal of Psychiatry 2012;200(5):374-80.

38 Oken RJ, Schulzer M. At issue: schizophrenia and rheumatoid arthritis: the negative association revisited. Schizophrenia Bulletin 1999;25(4):625-38.

39 Torrey EF, Yolken RH. The Schizophrenia-Rheumatoid Arthritis Connection: Infectious, Immune, or Both? Brain, Behavior, and Immunity 2001;15(4):401-10.

40 Leucht S, Burkard T, Henderson J, Maj M, Sartorius N. Physical illness and schizophrenia: a review of the literature. Acta Psychiatrica Scandinavica 2007;116(5):317-33. 41 Eaton WW, Pedersen MG, Nielsen PR, Mortensen PB. Autoimmune diseases, bipolar disorder, and non-affective psychosis. Bipolar Disorders 2010;12(6):638-46.

42 van 't Land H, Verdurmen J, Ten Have M, van Dorsselaer S, Beekman A, de Graaf R. The association between arthritis and psychiatric disorders; results from a longitudinal population-based study. J Psychosom Res 2010;68(2):187-93.

43 Cullen AE, Holmes S, Pollak TA, et al. Associations Between Non-neurological Autoimmune Disorders and Psychosis: A Meta-analysis. Biological Psychiatry 2019;85(1):3548.

44 Debnath M, Berk M, Leboyer M, Tamouza R. The MHC/HLA Gene Complex in Major Psychiatric Disorders: Emerging Roles and Implications. Current Behavioral Neuroscience Reports 2018;5(2):179-88. 
medRxiv preprint doi: https://doi.org/10.1101/2021.08.12.21261493; this version posted September 21, 2021. The copyright holder for this preprint (which was not certified by peer review) is the author/funder, who has granted medRxiv a license to display the preprint in

All rights reserved. No reuse allowed without permission.

45 Rege S, Hodgkinson SJ. Immune dysregulation and autoimmunity in bipolar disorder: Synthesis of the evidence and its clinical application. Australian \& New Zealand Journal of Psychiatry 2013;47(12):1136-51.

46 Rosenblat JD, Mclntyre RS. Bipolar disorder and immune dysfunction: epidemiological findings, proposed pathophysiology and clinical implications. Brain sciences 2017;7(11):144.

47 Karlson EW, Chang S-C, Cui J, et al. Gene-environment interaction between HLADRB1 shared epitope and heavy cigarette smoking in predicting incident rheumatoid arthritis. Annals of the rheumatic diseases 2010;69(01):54-60.

48 Karlson EW, Deane K. Environmental and gene-environment interactions and risk of rheumatoid arthritis. Rheumatic Disease Clinics 2012;38(2):405-26.

49 Uher R. Gene-environment interactions in severe mental illness. Frontiers in psychiatry 2014;5:48.

50 Van Os J, Rutten BP, Poulton R. Gene-environment interactions in schizophrenia: review of epidemiological findings and future directions. Schizophrenia bulletin 2008;34(6):1066-82.

51 Bergen S, O'dushlaine C, Ripke S, et al. Genome-wide association study in a Swedish population yields support for greater CNV and $\mathrm{MHC}$ involvement in schizophrenia compared with bipolar disorder. Molecular psychiatry 2012;17(9):880-6.

52 Mokhtari R, Lachman HM. The major histocompatibility complex (MHC) in schizophrenia: a review. Journal of clinical \& cellular immunology 2016;7(6).

\section{Figure legend}

\section{Figure 1.}

A. Scatter plot of single nucleotide polymorphism (SNP) potential effects on bipolar disorder versus rheumatoid arthritis. The $95 \%$ CI for the effect size on rheumatoid arthritis is shown as vertical lines, while the $95 \%$ CI for the effect size on bipolar disorder is shown as horizontal lines. The slope of fitted lines represents the estimated Mendelian randomization effect per method. B. Funnel plot for bipolar disorder shows the estimation using the inverse of the standard error of the causal estimate with each individual SNP as a tool. The vertical line represents the estimated causal effect obtained using IVW and MR-Egger methods. C. Scatter plot of SNP potential effects on schizophrenia versus rheumatoid arthritis D. Funnel plot for schizophrenia shows the estimation using the inverse of the standard error of the causal estimate with each individual SNP as a tool. 
Table 1. Two-sample Mendelian Randomization analysis of the effects of bipolar disorder, schizophrenia, and rheumatoid arthritis using

summary-level data.

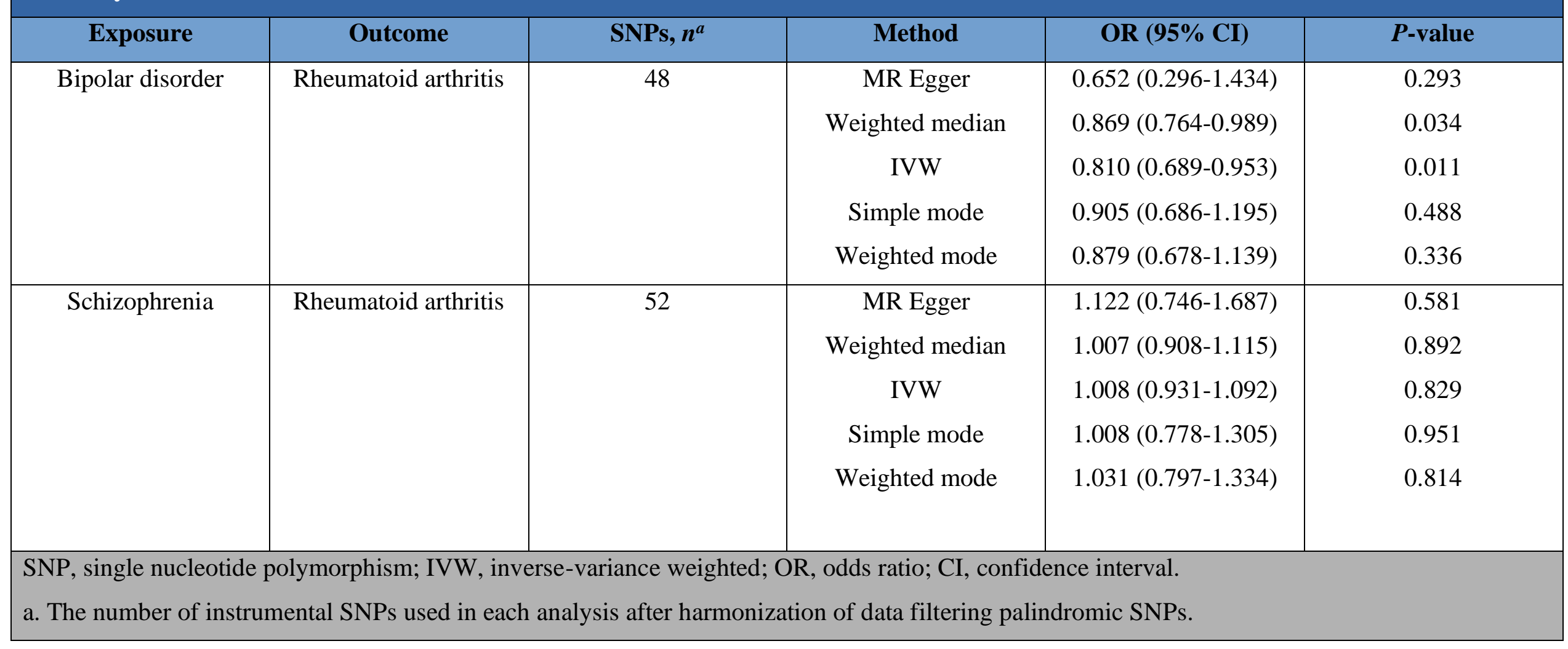


medRxiv preprint doi: https://doi.org/10.1101/2021.08.12.21261493; this version posted September 21, 2021. The copyright holder for this preprint (which was not certified by peer review) is the author/funder, who has granted medRxiv a license to display the preprint in All rights reserved. No reuse allowed without permission.

\section{Figure 1.}

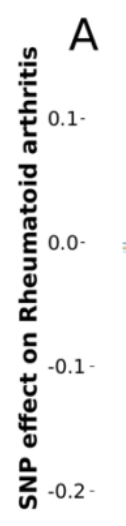

0.04

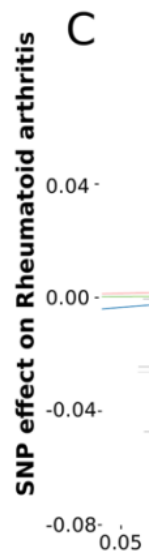

MR Test

Inverse variance weighted MR Egger Simple mode

B Weighted median
Weighted mode

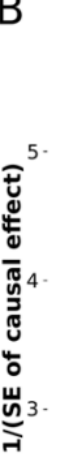

MR Method Inverse variance weighted IMR Egger

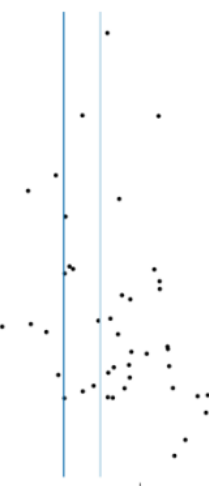

- i Individual causal effect $\begin{array}{ll}\text { Inverse variance weighted } & \text { Weighted median } \\ \text { MR Egger } & \text { Weighted mode } \\ \text { Simple mode } & \end{array}$ MR Test
Inverse variance weighted
MR Egger
D<smiles>[LiH]</smiles>

MR Method Inverse variance weighted

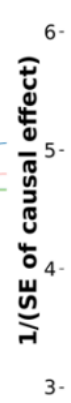
0.15 0.20 SNP effect on Schizophrenia

$-0.4$
0.4 